\title{
M-Learning Devices and their Impact on Postgraduate Researchers Scope for Improved Interaction in the Research Community
}

\author{
http://dx.doi.org/10.3991/ijac.v8i4.5024 \\ Emerson Abraham Jackson \\ University of Birmingham, Edgbaston, UK
}

\begin{abstract}
M-Learning is a widely topical concept in the $21 \mathrm{st}$ century, where people no longer need to worry about having to sit in a static location to explore new knowledge. This study have sought to explore the impact of M-learning devices like iPhone and a range of tablets on postgraduate researchers' ability to engage positively in the research community. In order to do this, efforts have been made to provide a range of definitions, and with some highlights of potential benefits and limitations of M-Learning devices in general Literature review on the topic was also explored, and with particular reference to virtual research medium in facilitating continuous support to postgraduate researchers seeking knowledge to engage themselves actively in research using all forms of technology, but specifically M-Learning devices. The distributed structured questionnaire helped immensely in enabling researchers to express their opinions both on the impacts of M-Learning devices on their ability to access resources and the diverse community of postgraduate researchers far and wide. Responses from the interview enabled association between variables to be explored and with recommendations proposed to address the way forward to assist postgraduate researchers increase their prospects of exploring and sharing ideas within the virtual research community.
\end{abstract}

Index Terms-M-Learning; E-Learning; Research Community; Technology; Personal Digital Assistant [PDA]; Correlation

\section{INTRODUCTION}

M-Learning is a common phenomenon used by researchers in the current Information Age, in which all aspects of people's lives is determined by access to portable devices of some sort. The use of desktop machines were very prevalent in the early eighties to the nineties but not so much flexible in their capacity to allow engagement with users across the world of academia. Different researchers have provided definition[s] to address the situation of M-learning in context:

El-Hussein and Cronje (2010), gave a concise interpretation of M-learning drawing upon Alexander study (2004), reflecting in context, the Higher Education setting "as any form of learning that happens when mediated through a mobile devices, and a form of learning that established the legitimacy of normative learners".

Behera (2013) research on the other hand, defined the concept of M-Learning as the "acquisition of any knowledge and skills through using mobile technology anytime, anywhere that result in alteration of behaviour".
In their research, Mahamad, Ibrahim and Taib (2010), concisely explained the concept of M-Learning as a new learning paradigm of the new social structure with mobile and wireless technologies. Commonly stressed point about the definitions cited is in relation to the 'mobility and flexibility' of M-Learning devices to users. This means that regardless of place or time, users can access information (whether online, audio or textual) on their device to further their knowledge or skills.

The use of M-Learning devices has brought about great benefits to users in the 21 st century age of advanced technology which includes; increase mobility for users, environmentally sleek design requiring less need for printing, ease of users time to acquire skills, scope for an enhancement in a wider audience of learners who may take an interest in sharing knowledge and the flexibility for users to decide on their preferred mode of interaction, for example, social interaction or listening to audio contents while on the move ${ }^{1}$.

\section{A. Distinctive feature between e-learning and $M$ - \\ Learning}

It is a common mistake for people and particularly the novice to think of M-Learning as simply e-learning. The commonality between them is the fact that users at some point in time needs access to the Internet to access resources. The highlighted points below provide a summary of the main distinctive features between e-learning and Mlearning (Mobl21: undated):

\begin{tabular}{|l|l|}
\hline \multicolumn{1}{|c|}{ E-learning features } & \multicolumn{1}{c|}{ M-learning features } \\
\hline - lecture in classrooms and Internet & - learning anywhere, anytime \\
labs & - Instantaneous messaging \\
- Email to email & - No geographic boundaries \\
- Private location & - No travel time with wireless \\
- Travel time to reach Internet site & internet connectivity \\
\hline
\end{tabular}

Lately, the use of portable devices such as smart cellular phones like iPhone, Samsung Galaxy and even tablets such as iPad, are all making it possible for learning to be made flexible and on-the-go with the advantage of WIFI

${ }^{1}$ El-Hussein and Cronje, 2010 and Behera, 2013. Based on Jackson [2015] study on the Learning Technologies, the use of M-Learning devices can also support learning flexibility.

Behera also went further to outline some of common limitations associated with the use of M-Learning technology / devices; limited storage capacity when compared to a laptop or desktop device, sometimes encounter issues of network connectivity, smaller LCD displays and creating strains on the users' eyes to adjust to contents and most obvious of it all, is its astronomical costs especially for new launch of device in the market and which then make it easier to be classed as outdated. 
facility to reach out easily to the virtual community from any location and at any time.

\section{B. M-Learning Community for Postgraduate Researchers}

M-Learning devices have contributed immensely to flexible means of access to learning opportunities for postgraduate researchers who, in centuries gone were entwined in a situation of isolation during their pursuance for new contributions to a discipline of knowledge.

Traxler (2011) explained the emergence of "MLearning in the UK, and also in the EU and Northern America as a legacy from its respective community of elearning". The flexibility attributed to learning devices, and more so portable items like mobile phones meant that learning is no longer restricted to the confines of a restricted location which is dependent on access to the connection of Internet port or network. In developed economies such as the UK, and its EU / Northern American counterparts have seen an escalation in the use of $M$ Learning devices to help drive / foster postgraduate researchers' interests in integrating with a wide pool of researchers through various medium like social networking sites and more research intensive communities like 'Research-Gate' and facebook community for academic discussion groups.

Research intensive community such as Research-Gate have made it possible for researchers across remote communities around the world to take themselves in proactive steps to engage with colleagues in the research community using flexible devices like mobiles phone while on the go. There is a wide pool of researcher across the world who seemed to be making active use of mobile friendly devices to access the research community so as to enable them to raise pertinent questions involving research tasks.

\section{Hypothesis:}

The research has been developed on the main premise that M-Learning devices is making a headway in enhancing flexibility in learning opportunities for postgraduate researchers and through this, they have been able to make use of wide range of mobile devices to penetrate into the online community to further their quest for knowledge through questions posed to participants in the virtual research community.

Therefore, the question for this study is stated thus: Does access to internet ready M-Learning devices helps researchers increase their scope to the research community?

\section{Research Aim and Objectives}

This research seeks to explore correlation between Mlearning usage and their desired usage in supporting the postgraduate researcher's scope to integrate well, particularly in terms of accessing resources and also, actively engaging with other researchers on research-based topical issues.

- Explore the relevance of M-learning devices to the postgraduate researcher regardless of location.

- Assess level of correlation between internet ready Mlearning device usage and their scope in fostering researchers' integration into the community of higher knowledge.

\section{A REVIEW OF LITERATURE ON M-LEARNING}

With the advent of the information age, and more so in the late nineties to present day, learning seemed to be taking a different dimension to such an extent that, learning no longer need to take place in the confine of a fixed location, as most users are now resorting to using $\mathrm{M}$ Learning devices like iPhone, iPad and other forms of tablets to explore their quest for knowledge. As illustrated in Herrington and Herrington's [2007] study report, the expansion of mobile technology in education is very much linked to educational theories as outlined below:

1. Behaviourist theory activities that promote learning as a change in observable actions - with the use of mobile phone and PDA for learning language.

2. Constructivist - activities in which learners actively construct new ideas or concepts based on previous and current knowledge - e.g., environmental detection using GPS.

3. Situated learning activities that promote learning within an authentic context and culture - e.g., role playing using mobile phone.

4. Collaborative learning activities that promote learning through social interaction - e.g., use of PDA by teachers to beam questions.

5. Informal \& lifelong learning activities that promote learning outside a dedicated learning environment and formal curriculum - use of mobile phone to deliver interaction.

6. Learning and teaching support activities that assist in the coordination of learners and resources for learning activities - e.g., use of PDA to retrieve courseware or providing feedback to students.

As explained by Herrington and Herrington [2007], Mtechnology usage in higher education, is still considered to be didactic, rather than taking a 'constructivist approach', and as such, their interpretation is viewed as regressive.

Higher education throughout the developed nations, particularly in the US and UK are now encouraged to use electronic means of learning [Kissinger, 2013], particularly with the use of e-book as a cost-saving means and the development of M-learning technology which is now easing the students' ability to access learning materials anywhere, and at any point in time. In most cases, these materials can also be downloaded and read offline by users which reduce pressure on those learners, who for some reason cannot afford the cost of 24 hours internet access.

El-Hussein and Cronje (2010) addressed a tripartite interpretation of M-learning devices which includes "mobility of technology, mobility of learner and mobility of learning" in the H.E sector. In their study, they made clear reference to Trinder's [2005. p. 7] diagram as shown below, with features that allow users to be able to make active use of mobile devices for easy means of flexible learning.

\footnotetext{
${ }^{2}$ That which allows individual to be more proactive in using their knowledge to develop knowledge through the use of mobile led-devices such as PDA
} 


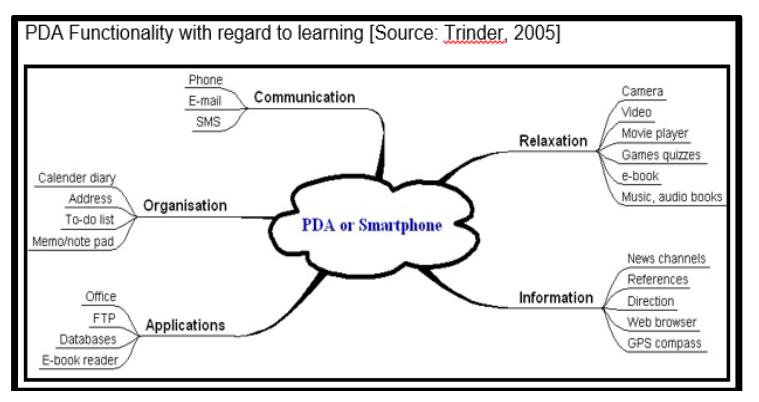

With reference to the above diagram, the use of $\mathrm{M}$ Learning device[s] such as a PDA or smart phone brings with it extra benefit to the user, for example, easy means of communication [with the use of email, SMS and voice], comfort to the user [with incorporated features like camera, video and even e-book for a user to save downloadable materials], organisation of work schedule, and particularly in relation to postgraduate researchers [user of incorporated features like diary, address book and note pad], incorporated applications [Office compatible features] and information reference [such as web browser for the user to access internet materials at the location of their convenience].

\section{METHODOLOGY OF INQUIRY}

\section{A. General Methodology \& the Study Community (Population and Sample)}

The study was initiated on the main premise of finding out the associated impact of Internet-ready M-Learning device(s) on postgraduate researchers' scope of reaching out [far and wide] to the research community. In order to do this, the study then developed a survey approach using online platform such as personal email contacts, CANVAS, Research-Gate and Twitter to reach out to the intended participants. Despite the limitation of the adopted method, the use of virtual medium to access participants was considered one of the preferred medium because, it was considered a low cost means of reaching out to the targeted population group (in this case, postgraduate research students).

A total of 35 questionnaires were distributed to 'postgraduate researchers ${ }^{3}$ in the four major continents (Africa, Asia, Europe and America). Greater response emphasis was given to researchers from the African continent as it is still perceived as the region where internet access for higher education is restricted due to poor investment by national governments. The intention was to get up to 30 responses (approximately 86\%) from postgraduate researchers across the study community, which incorporate researchers based in the identified population regions. Despite other questions were asked, which involved basic statistical interpretations, the main focus was geared toward exploring correlation between ready Internet $\mathrm{M}$ Learning devices, amount of time spent on the internet and accessibility to the research community.

\section{B. Study design}

The design was set purely to mirror an 'action research' ${ }^{\prime 4}$ approach, with questions posed specifically to postgradu-

\footnotetext{
${ }^{3}$ Purely those on research-only intensive courses such as MA, M.Sc, $\mathrm{PhD}$ and other professional doctorate courses

${ }^{4}$ Robson (1997) - it incorporate a spiral of planning, acting, observing and reflective approach on the part of the researcher with his / her in-
}

ate researchers about their use of online community to enhance their research capacity. These were then extracted for analysis with the aim of establishing degree of correlation / regression between identified variables. Likertscaling ${ }^{5}$ style questions were also used to address concepts involving the exploration of correlation between variables, and with some straightforward questions requiring 'Yes / $N o^{\prime}$ response(s), and the region / location of participants whiles engaging in their research studies.

\section{Limitations}

The research was limited in its scope of reaching out to more participants far and wide. Responses took longer than expected to be returned, and the analysis was mainly done using limited feature of MS Excel rather than a more sophisticated application like SPSS / Stata.

\section{ANALYSis Of ReSUlt AND Discussion}

The analysis was conducted using advanced add-in feature like Correlation in MS Excel application and backed by simple descriptive statistics like percentages to gauge rate of responses. The emphasis was focused on the 'Pearson's product-moment correlation ( $r)^{\prime}$ to determine degree of relationships relating to questions 5,6 and 7 on the questionnaire. The r-statistic may take either positive or negative direction illustrated simply in linear form [-1 to 0 to +1$]$. The closer the r-coefficient towards \pm 1 , regardless of the direction, the stronger the coefficient of association, whereas $\mathrm{r}=0$, indicates no association ${ }^{6}$. A positive correlation would indicate that an increase in the first variable would result in an increase in the second variable, thus resulting in a direct relation between the two variables. On the converse, a negative coefficient of $r$ would still imply a degree of relationship, but indirect with an increase in the first variable resulting in a decrease in the second. One limitation associated with the use of the Pearson's correlation is that it does not show degree of non-linearity between the variables examined, and therefore, may result in some form of false reaching conclusion of cause-andeffect in the existentiality of the degree of relationship ${ }^{7}$.

Causation effect (As x increase, y also increase)!!!

\section{A. Result and Discussion}

Based on the order of questions in the questionnaire, a straightforward statistical interpretation was used for ' $Q \mathbf{1}$ to $\mathbf{Q 4}^{\prime}$ as summarised below. Question 1 shows $82 \%$ of Male responding Yes to their access to Internet ready MLearning device as opposed $18 \%$ of Female usage for their postgraduate research studies. With reference to question 2 which deals with location of participant, the information below provide a summary of the analysis.

volvement with the research community. This method to no surprise, have also come under intense criticism by researchers like Adelman (1989), who sees it as inward looking and 'ahistorical', the likelihood of poor quality due to its limited scientific approach. Despite this criticism, the advantage to this research is that, it provide the scope by which MLearning usage to postgraduate can be explored in the light of enabling them to achieve their desired end goal of achieving a valuable research qualification.

${ }^{5}$ Ibid - Otherwise known as 'the summated rating', was developed in the 1930s by Likert, with its advantage of incorporating differentiated ratings within questions posed or concepts.

\footnotetext{
${ }^{6}$ Taylor (1990)

${ }^{7}$ Ibid.
} 
Africa: $15 \%$

Asia: $6 \%$

Europe: $33 \%$

N. America: $28 \%$

S. America: $5 \%$

Pacific (Australia / New Zealand): 3\%

Surprisingly, a lot more postgraduate researchers from the African continent seemed to be actively engaged in research intensive learning. The $15 \%$ outcome can be highly linked to the author's interaction with researchers from the African continent, and his own background as an African.

Analysed response for Question 3, in relation to type of postgraduate research course is provided below.

MA: $3 \%$

MSc: $7 \%$

$\mathrm{PhD}(\mathrm{pt} / \mathrm{ft}): 45 \%$

PhD (dist): $12 \%$

Prof. Doct.: $33 \%$

Higher percentage [ $90 \%$ for all doctorate responses] of the responses indicate enrolment on a postgraduate doctorate researchers study.

Analysed response for Question 4, indicate the following summarised results:

Yes: $87 \%$

No: $13 \%$

It is quite obvious that more postgraduate researchers are becoming more reliant on M-Learning device[s] of some sort to progress on with their research work, which indicate flexibility in their approach to accessing learning materials and also engaging with the wider research community.

Questions 5 to 7 as shown in the analysed table below, provide a statistical coefficient of degree of relationship between variables.

The result indicate a very strong positive relationship (0.92 approximately) between Internet ready M-Learning device and potential of postgraduate researcher to access the virtual research community for support. There is approximately 0.6 degree of strength in relationship between hours spent and ready Internet M-Learning device. This is a reasonably strong relationship, and such average strength in relationship may likely be explained in terms of quality of time spent rather than the length of time spent by a postgraduate researcher accessing information on an M-Learning device. There is also approximately a 0.6 strong degree of relationship between hours spent and the potential for postgraduate researchers to access information on their M-Learning device.

As explained by Taylor (1990), the limitation of the correlation coefficient outcomes from Q5-Q7 must not be ignored as the result did not show a clear explanation of unexplained non-linearity in the relationships. On a positive note, the outcomes revealed a good base to explore further the usage and potential benefits of Internet ready M-Learning devices to postgraduate researchers regardless of the location / country in which they may choose to pursue their studies.

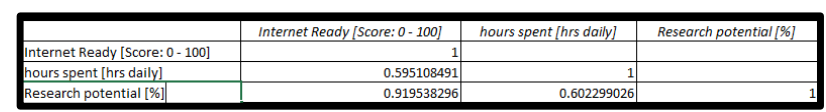

Basic statistical percentage was used to interpret result for Question 8 with outcome showing 93\% [with the remaining 7\% stating $\mathrm{No}$ as a response] of potential respondents recommending Internet M-Learning as a good means of helping postgraduate researchers access the research community for resources. This is very important as it serve as a good base to explore further the relevance of mobile devices, not only to the researchers in the higher education sector, but also as a means of developing research potential for learning in schools and the wider world of work. It actually addresses the real concerns faced by postgraduate researchers with respect to fear about the virtual world of work, particularly those who have stated NO in their response.

\section{CONCLUSION AND RECOMMENDATIONS}

In conclusion, this study has provided a starting point of exploring the potential relevance of Internet M-Learning device to the research community. The analysis also reveal that the availability of portable learning device does not necessarily lead to an increase time spent but more so about quality of usage in ensuring substantive research is carried out to help researchers' explore their knowledge quest in the virtual community.

On this note, and particularly with reference to question 8 on the questionnaire, it is quite evident that M-Learning devices of all sorts are very essential to the postgraduate researcher, more so in terms of their flexibility in accessing information in the virtual community. A further investigation will be very useful to explore specific focus on the relevance of $\mathrm{M}$-learning devices in supporting the distance learning researcher to make substantial progress through constructive feedback from research supervisors.

\section{ACKNOWLEDGEMENTS}

I wish to express my sincere thanks to family members for their support in inspiring me through the process of undertaking this study, and last but not least, to everyone who would have responded to questions posed on the via the social media.

\section{REFERENCES}

[1] Adelman, C. (1989). The Practical Ethic Takes Priority over Methodology. In W. Carr (ed.), Quality in Teaching: arguments for a reflective profession. London: Falmer. 440, 441.

[2] Behera, S.K (2013). M-LEARNING: A NEW LEARNING $P A R A D I G M$. International Journal on New Trends in Education and Their Implications, 4 (2), 24 - 34

[3] El-Hussein, M.O.M and Cronje, J.C (2010). Defining Mobile Learning in the Higher Education Landscape, Educational Technology and Society, 13 (3), 12 - 21.

[4] Herrington, A., \& Herrington, J. (2006). What is an authentic learning environment? In A. Herrington\& J. Herrington (Eds.), Authentic learning environments in higher education (pp. 1-13). Hershey,PA: ISP. http://dx.doi.org/10.4018/978-1-59140-594-8

[5] Jackson (2015). Impact of MOODLE platform on the pedagogy of students and staff: Cross-curricular comparison. Education and Information Technologies Journal. http://dx.doi.org/10.1007/ s10639-015-9438-9

[6] Kissinger, J.S (2013). The Social \& Mobile Learning Experiences of Students Using Mobile E-books, Journal of Asynchronous Learning Networks, Volume 17 [1]: 155 - 170.

[7] Mobl21 (Undated). Mobile Learning Basics (Online). Available at: <http://www.mobl21.com/Basics_Of_Mobile_Learning.pdf $>$. [Accessed: 17th May 2015].

[8] Mahamad, S, Ibrahim, M. N and Taib, S. M (2010). MLEARNING: A NEW PARADIGM OF LEARNING 
MATHEMATICS IN MALAYSIA, International Journal of Computer Science and Information Technology, 2 (4), 76 - 86. http://dx.doi.org/10.5121/ijcsit.2010.2407

[9] Robson, C (1997). REAL WORLD RESEARCH: A Resource for Social Scientists and Practitioner-Researchers, Oxford: Blackwell Publisher.

[10] Taylor, R (1990). Interpretation of the correlation coefficient: A basic review. Journal of Diagnostic Medical Sonography (JDMS), 6(1): 35 - 39. http://dx.doi.org/10.1177/875647939000600106

[11] Traxler, J (2011) Introduction. In: Traxler, J and Wishart, J. (eds) Making Mobile Learning Works: Case Studies Practice, pp. 4 - 12. Available at: $<$ http://escalate.ac.uk/downloads/8250.pdf $>$. [Accessed: 17th May 2015].

[12] Trinder, J. (2005). Mobile Technologies and Systems. In A. \&. Kuklska-Hulme (Ed.), Mobile learning: A handbook for educators and trainers, USA: Taylor \& Francis.

\section{AUTHOR}

Emerson Abraham Jackson is a research doctorate (distance learning) student in the Centre of West African Studies, University of Birmingham, Edgbaston, Birmingham B15 2TT, UK (e-mail: author@nrim.go.jp).

This work was carried out as a result of the author's interests in Information and Communication Technologies, and in addition, as an ongoing Action Researcher in a multi-disciplinary field of studies [Social Sciences and Education]. Manuscript received 09 August 2015. Published as resubmitted by the author 30 November 2015 .

\section{APPENDICES}

\section{APPENDIX 1: QUESTIONNAIRE}

Q1. Please specify your gender.

Male

Female

Q2. Which continent are you currently studying from?

Africa

Asia

South Pacific (Australia / New Zealand)

Europe

North America

South America

Q3. What level of postgraduate research course do you pursue?

MA by research

MSc by research

$\mathrm{PhD}$ (full / part time)

$\mathrm{PhD}$ (distance learning)

Professional doctorate (Please specify.....)

Q4. Do you have possession of M-Learning (hand-held) device to help you with your research work?

Yes

No

Q5. If Yes, please rate the degree of Internet ready or accessible (with Wifi feature) on a scale of $0-100 \%$ ?

Response:.

Q6. Please specify on average number of hours spent per day.

Response:

Q7. Please rate the degree of its potential usage for your research undertakings to access the virtual research community.

Response:

Q8. Would you recommend it as a means of engaging easily with the research community?

Yes

No
APPENDIX 2: RESUlt TABLE FOR Q5 - Q7

\begin{tabular}{|c|c|c|}
\hline Internet Ready [score:0 - 100] & Hours spent per day [out of 24 hrs] & Research potential [\%] \\
\hline 90 & 15 & 90 \\
\hline 85 & 18 & 95 \\
\hline 75 & 19 & 80 \\
\hline 75 & 14 & 80 \\
\hline 50 & 13 & 50 \\
\hline 955 & 19 & 95 \\
\hline 75 & 14 & 80 \\
\hline 65 & 14 & 75 \\
\hline 68 & 15 & 78 \\
\hline 98 & 16 & 92 \\
\hline 90 & 20 & 93 \\
\hline 80. & 15 & 80 \\
\hline 83 & 16 & 90 \\
\hline 90 & 16 & 95 \\
\hline 65 & 15 & 76 \\
\hline 90 & 16 & 95 \\
\hline 84 & 17 & 90 \\
\hline 74 & 15 & 85 \\
\hline 80 & 15 & 90 \\
\hline
\end{tabular}

